e-ISSN: $1984-4255 \quad$ ARGUMENTOS

DOI: $10.36517 /$ Argumentos.26.6

\title{
As concepções africanas do ser humano: leituras à partir da Bantu Philosophy de Placide Tempels
}

\section{African conceptions of the human being: critical readings from the Bantu Philosophy of Placide Tempels}

\author{
Tiago Tendai Chingore \\ https://orcid.org/0000-0001-8227-1637 - E-mail: ttendaigamachingore@gmail.com \\ Elnora Gondim \\ https://orcid.org/0000-0002-4690-131X - E-mail: elnoragondim@yahoo.com.br
}

\section{RESUMO}

O artigo debate sobre as concepções africanas do Ser humano a partir da Bantu Philosophy de Placide Tempels, partindo da obra African Philosophy: Myth and Reality. Procuramos fazer uma desconstrução e construção da crítica avançada, à etnofilosofia de Placide Tempels na sua obra Bantu Philosophy (Filosofia Bantu). Portanto, falar de Placide Tempels evoca, de certo modo, toda uma série de questões e debates que estão intimamente relacionados com a existência da primeira tentativa de construir e sistematizar a filosofia africana. Na verdade, não se pode falar da filosofia africana sem fazer menção à Tempels em sua obra Bantu Philosophy de 1945. Tempels foi o primeiro autor que trouxe a questão de filosofia "Bantu" à superfície. Neste contexto, a obra African Philosophy: Myth and Reality de Paulin Hountondji, criou um movimento intelectual bastante forte, que despoletou debates filosóficos fervorosos nos últimos anos. No seu prefácio, Hountondji inicia o debate considerando Husserl, como sendo o filósofo que teria criado algumas formas, técnicas e ideias intelectuais que permitiram a filosofia de ser uma ciência rigorosa. Na mesma linha de pensamento, Hountondji evoca René Descartes no seu Cogito ${ }^{1}$, onde

\footnotetext{
1 Cogito - em Descartes, designa a primeira verdade que, graças à sua evidência, resiste à dúvida metódica. Literalmente, designa "jê pense, jê suis"“Eu penso, eu sou". Para Descartes esta verdade era tão sólida e tão segura que nem as suposições mais extravagantes dos céticos seriam capazes de abalá-la, podia recebê-la sem escrúpulos por primeiro princípio da filosofia que procurava.
} 
defendia que todas as doutrinas deveriam possuir um valor, uma responsabilidade intelectual e uma justificação lógico-racional. Para tanto, o trabalho apresenta-se estruturado em duas partes, onde na primeira parte: faço uma fundamentação do pensamento de Placide J. Tempels e da sua teoria sobre a Filosofia Bantu, descrevo seu perfil, sua concepção de ontologia Bantu e a sua visão em torno da filosofia bantu. Na segunda parte, apresento a ideia proposta por Paulin Hountondji e a sua crítica unanimista à etnofilosofia de Tempels, onde apresento as influências que ele teve, a crítica que faz à etnofilosofia de Tempels, aqui invoco vários filósofos africanos que abordam sobre o tema em estudo, e, por fim, as considerações finais.

Palavras-chave: Filosofia Africana. Etnofilosofia. Ontologia. Força vital. Ser Humano.

\begin{abstract}
The article discusses the African conceptions of the Human being from the Bantu Philosophy of Placide Tempels, starting from the work African Philosophy: Myth and Reality. We seek to deconstruct and construct advanced criticism, to the ethnophilosophy of Placide Tempels in his work Bantu Philosophy (Philosophy Bantu). Therefore, speaking of Placide Tempels evokes, in a way, a whole series of questions and debates that are closely related to the existence of the first attempt to construct and systematize African philosophy. In fact, one cannot speak of African philosophy without mentioning Tempels in his Bantu Philosophy (1945). Tempels was the first author to bring the "Bantu" philosophy issue to the surface. In this context, the work African Philosophy: Myth and Reality by Paulin Hountondji, created a very strong intellectual movement, which triggered fervent philosophical debates in recent years. In his preface, Hountondji begins the debate by considering Husserl, as the philosopher who would have created some forms, techniques and intellectual ideas that allowed philosophy to be a rigorous science. In the same line of thought, Hountondji evokes René Descartes in his Cogito, where he argued that all doctrines should have a value, an intellectual responsibility and a logical-rational justification. To this end, the work is structured in two parts, where in the first part: I provide a foundation for the thinking of Placide J. Tempels and his theory on Bantu Philosophy, I describe his profile, his conception of Bantu ontology and his vision around Bantu philosophy. In the second part, I present the idea proposed by Paulin Hountondji and his unanimous criticism of Tempels 'ethnophilosophy, where I present the influences he had, the criticism he makes of Tempels' ethnophilosophy, here I invoke several African philosophers who address the subject under study, and, finally, the final remarks.
\end{abstract}

Keywords: African philosophy. Ethnophilosophy. Ontology. Vital force. Human being.

\title{
Nota introdutória
}

Para iniciar esta reflexão, importa avançar algumas questões de partida: será se existe uma humanidade especificamente africana? E se sim, qual é o lugar epistemológico a partir do qual se pode formular uma tal especificidade antropológica? O início da filosofia africana contemporânea mistura-se e confunde-se com o início da teologia africana. Deve-se reconhecer que a especulação filosófica de muitos filósofos da primeira hora, que eram também teólogos, era movida pelo objectivo de adaptar ou inculturar o cristianismo nas terras de África (Philosophia ancilla Theologiae). Os filósofos africanos sucessivos operaram uma crítica da crítica, superando 
os limites da crítica à etnofilosofia que tinha constantemente o olhar voltado ao passado. $O$ paradigma libertário de Severino E. Ngoenha vai mesmo nessa direcção. A Filosofia Africana quer olhar para o presente e o futuro, recuperar filosoficamente as tradições para transformar a realidade e entrar em diálogo com o resto do mundo (BONO, 2019, p. 93). Desde 1945 existe em África um debate dialéctico vivo em volta da filosofia africana que não cessou de incrementar-se. Em outras palavras, durante muito tempo ocorreu um debate rico e contraditório em volta da questão de sua própria existência e do eu estatuto epistemológico e científico. Entretanto, nos últimos anos, na filosofia africana, discutem-se problemas do estatuto moral e científico da antropologia, da relação entre a tradição e a modernidade, da relação entre a oralidade e a escrita, da natureza das nossas democracias. dos impasses do desenvolvimento, etc.

Para Ngoenha (2010), "os intervenientes em termos de áreas culturais hoje não são só francófonos e anglófonos, mas são também lusófonos, aos quais depois do apartheid vieram ajuntar-se a África do Sul que mesmo sendo anglófona tinha ficado a margem dos debates do continente". Assim, quando se percorrem as grandes linhas deste debate filosófico africano como ele se desenrolou na segunda metade do século, identificam-se claramente três lugares de discurso a partir dos quais uma figura do homem africano se construiu: o pensamento tradicional ou a cultura oral; os discursos antropológicos como se construíram a partir do século XIX, o pensamento africano (sapiente), isto é, a reflexão dos intelectuais africanos sobre a própria identidade (NGOENHA, 2010, p. 183).

As concepções do ser humano invocam em primeiro lugar, a antropologia, mas dado que outras antropologias nasceram no século XIX, ocorre precisar que se trata do que tradicionalmente se chamava antropologia filosófica a partir da tese: "Cada vez que um velho morre, é uma inteira biblioteca que se queima".

Contra a primazia e a superioridade suposta da escrita sobre a oralidade, Hampatê Bâ sugere um duplo postulado. Primeiro, que os anciãos são depositários de um saber que é equivalente aos arquivos e a biblioteca tanto defendidos por Paulin Hountondji (1977), ao ponto de fazer deles a condição necessária para a existência de uma filosofia africana. Em segundo lugar, Hampatê Bâ parece defender a tese segundo a qual, não existiriam critérios objectivos para comparar a escritura e a oralidade. Por conseguinte, a oralidade não seria necessariamente inferior a escrita, mas um saber diferente cuja importância só podia ser pertinentemente avaliada por aqueles, ou a partir daqueles, cujas vidas são animadas por ela. Mas por outro lado, "por detrás da oralidade se esconde não simplesmente a apreciação subjectiva e adjectivante das pessoas e grupos culturais por ali animados, mas a oralidade pode compreender uma sabedoria e até mesmo uma filosofia" (NGOENHA, 2010, p. 184).

Uma figura emblemática que encontramos no início da filosofia (e teologia) africana é, sem dúvida o não africano, Placide Tempels, um missionário belga que depois de dez anos vividos no Congo, em 1946 publica a La Philosophie Bantu (A Filosofia bantu).

Contudo, foi a partir desta obra, que seguirão várias reações críticas. Apesar destas críticas, a importância desta obra, senão do ponto de vista filosófico, pelo menos histórico, está em ter marcado o início do debate filosófico africano contemporâneo. Entre os primeiros críticos de Tempels encontramos um grande filósofo, Alexis Kagamé, o qual criticou a obra de Tempels, tanto do ponto de vista formal, e segundo ele, (trata-se de uma obra mais etnológica do que filosófica), e do ponto de vista material (uma pesquisa limitada a uma só tribo africana), e propõe na sua obra La Philosophie bantu-rwuandaise de l'Être (A filosofia Bantu Ruandesa do Ser), onde reivindica a capacidade das línguas bantu de exprimir conceitos abstractos e por isso, são línguas capazes de filosofar. 
Para ele, o princípio vital do Muntu (pessoa), na dupla dimensão (da inteligência e da vontade que permitem o alcance do seu fim determinado pela sua forma de macho e fêmea), é a procriação. E este princípio vital vai sendo legado de geração em geração e também depois da morte, através dos antepassados (BONO, 2019, p. 87). Um outro crítico que, mesmo reconhecendo os méritos de Tempels, nega com determinação a sua ideia de força vital, é Vicent Mulago.

Contudo, em uma declaração autobiográfica, Tempels descreveu-se nos primeiros anos como missionário assim: "Eu vim para a África em 1933 como um cidadão europeu, como uma pessoa branca na África colonizada e, o que é mais importante, eu acreditava que era o mensageiro com uma mensagem do Alto". Assim, ele tinha um objectivo, ver e sentir o Bantu pelo menos uma vez na vida. Ele queria pensar, sentir, viver como eles, ter uma alma Bantu. Uma vez conseguido ver e sentir a vida com eles, iria assumir sua personalidade europeia novamente, onde, então, falaria uma língua. No entanto, Tempels considera ter sido um grande esforço para confiar a sua personalidade a do outro, o homem Bantu, este alcançado se expressaria claramente, e também descobrir-se-ia pela primeira vez através da reflexão (TEMPELS, 2006, p. 12).

O conceito Bantu foi apresentado pela primeira vez em 1850, por um pastor teólogo Wilhelm Bleek. A sua pesquisa estava mais virada às questões linguísticas que significavam povo. E só mais tarde é que Placide Tempels teria herdado e alargado toda uma série de questões sobre a mitologia bantu na sua obra filosófica intitulada Bantu Philosophy (Filosofia Bantu) de 1945. Foi nesta obra, onde a ideia da ontologia bantu reside no conceito da Força Vital. Aqui, Tempels iniciou seu trabalho ao criticar o pré-logismo de Lévy-Brul, e percebe-se que os negros apresentam um sistema de princípios e que o comportamento bantu deve ser considerado racional como qualquer outro comportamento, motivo pelo qual não se pode rejeitar nem duvidar da existência da humanidade do homem negro.

Aqui Tempels expunha o que considerava ser a metafísica da força vital dos Bantus. A força vital seria para os Bantus o único valor fundamental, identificável com a existência. Assim sendo, todo ser é dotado de força vital, ou melhor, é uma participação da força vital e a sua vitalidade é variável. Dai a tese: Sou porque somos; dado que somos todos, também eu sou². Isto significa que os seres humanos se encontram no centro do tecido vital e a geração presente na terra constitui o centro da humanidade inteira que inclui mortos e os ainda não nascidos. $\mathrm{A}$ natureza deve servir para melhorar e perpetuar a vida, a cultura, a religião e todas as instituições do saber humano estão orientados a este mesmo propósito: favorecer a vida e superar todo e qualquer perigo para a vida.

Nesse sentido, duma forma geral, pode-se dizer que vários escritores africanos defendem a não existência de uma ordem dual da realidade. Porém, defendem a existência de uma hierarquia dentro da ordem unitária do universo. Esta hierarquia compreende Deus, os antepassados, os espíritos, o homem e a natureza. Não há dicotomia entre matéria e espírito, sagrado e profano, natural e sobrenatural, comunidade e indivíduo, sujeito e objecto. Por isso, o universo africano é um todo, os africanos viveriam em simbiose com Deus e com a natureza (NGOENHA, 2010, p. 191).

Ainda na mesma perspectiva, Tempels defende que o comunalismo é a característica africana mais destacada por um número considerável de intelectuais africanos. Como refere Etounga Manguelle apud Ngoenha (2010, p. 191), "se se tivesse que citar uma única caracterís-

\footnotetext{
2 Slogan proposto por John Mbiti, que se tornou paradigma para discussão do homem africano, tanto para os seguidores como os detratores. O indivíduo não só não existe e não pode existir se não corporativamente, mas ele deve a sua existência aos demais, e até somente através de outras pessoas ele chega ao conhecimento do seu próprio ser. O indivíduo não tem por si mesmo, nem existência, nem consciência do ser; só pode tê-los no grupo.
} 
tica da cultura africana, o ponto de referência fundamental seria o desaparecimento do indivíduo face a comunidade".

No entanto, por Filosofia Africana, Hountondji define a como sendo "um conjunto de textos, textos que são especialmente escritos por africanos e descritos como sendo filosóficos pelos próprios autores" (HOUNTONDJl, 1996, p. 9). O crítico da etnofilosofia avança na sua obra três (3) aspectos levantados contra aquilo que vários leitores consideram e definem como filosofia africana, a saber: Em primeiro lugar, que a nacionalidade e a localização geográfica do autor, não é condição suficiente para a africanidade, mas sim, sugere que algo a mais se deve incluir ligado à causa africana; Em segundo lugar, as intensões pessoais do autor e a sua auto-crítica não deve constituir razão suficiente para designar um trabalho qualquer de filosófico; e por fim, a objeção mais contundente, faz menção à quantidade de textos escritos, a restringir, o que de certa forma é arbitrário e ambíguo. Outro sim, são as formas de expressão filosóficas e a falta de atenção que se dão às expressões da literatura oral que são extraordinariamente ricas.

Nesse contexto, é preciso abrir o horizonte das nossas mentes, rejeitando qualquer definição da filosofia africana que poderia implicar restrição ou mesmo poluição, ao confinar o africano a um conceito, ideologia, religião ou política de estrangulamento e reforçaria uma crença ilusória de que um destino inflexível seria algo que ficaria patente para sempre (HOUNTONDJI, 1996, p. 12). O autor toma como exceção na sua obra a inconsistência da teoria do consciencismo de K. Nkrumah; rejeitando a concepção da filosofia como um comentário ideológico na política.

Uma crítica mais aprofundada à identificação do ser com a força encontramos em Fabien Eboussi Boulaga, um dentre os maiores e mais cultos filósofos (e teólogos) africanos. “Reconhecer ao Muntu a capacidade de filosofar não é um elogio, mas uma reafirmação do desprezo para com o africano. O Muntu, libertado da independência conceptual do Ocidente, apropria-se do discurso sobre si, recomeçando da tradição renovada" (BONO, 2019, p. 70). Contudo, o crítico mais feroz foi sem dúvida Hountondji que afirma que a filosofia bantu é uma invenção dos europeus que assim operaram uma colonização mental da qual há necessidade de se libertar:

Em síntese: a etnofilosofia é uma filosofia na acepção de visão do mundo genericamente africana; o seu objecto é a reconstrução ontológica de concepções tradicionais, projetadas numa dimensão numa dimensão a-histórica e dotadas de necessidades metafísica; o seu postulado implícito, censurado, é a ideia de uma humanidade primitiva, o seu mito de fundação. Trata-se de uma invenção europeia, cujo escopo é domesticar os povos colonizados, induzindo à introjeção da independência, graças à exaltação de uma identidade fictícia que seja agradável às ideologias colonialistas.

Como podemos ver, a rejeição da Filosofia Bantu (de Tempels) deveu-se não só a motivos epistemológicos, mas sobretudo políticos.

A identidade da filosofia, também, diz respeito à questão da sua origem. Como defende o historiador Cheik Anta Diop, a origem negra da filosofia encontra-se no Egipto, composto pela raça bantu. Esta, por sua vez, influenciou de certo modo o surgimento da filosofia na Grécia. Deste modo, a filosofia africana como apêndice seria recolocada no centro (ou no início) da história da filosofia mundial. Esta conclusão de Diop engaja-se e supera o dilema que ocupou por dezenas de anos o debate da filosofia em África em relação à existência de uma filosofia africana.

No entanto, como defende Ramose apud Bono $(2019$, p. 93) a base da filosofia africana é a ideia de ubuntu. Por seu turno Crahay apresenta cinco condições para que haja de facto uma filosofia africana: Primeiro, um corpo de filósofos e intelectuais africanos que vivem e trabalham num ambiente cultural africano, mais aberto ao mundo; Segundo, usar bem criticamente as re- 
flexões da filosofia académica ocidental; Terceiro, fazer um inventário dos valores africanos; Quarto, operar uma rutura radical entre a consciência reflexiva à consciência dos mitos que permitia introduzir a dicotomia necessária para a "descolonização conceptual" (o que a etnofilosofia não conseguiu fazer); Quinto, clara opção de sistemas filosóficos adequados à solução dos problemas africanos (como foi o marxismo na luta armada).

\section{A ideia da Ontologia Bantu proposta por Tempels}

Tempels inicia por dizer que, antes de começar a definir a filosofia do Bantu, temos de justificar o uso dos termos que iremos empregar. Mesmo que fosse empregar uma tradução literal dos termos Bantu, devemos explicar ao leitor não iniciado a força exacta dessas expressões nativas. O estudo sobre a filosofia Bantu, apesar de tudo, pretendia ser mais do que uma hipótese, uma primeira tentativa de desenvolvimento sistemático de que a filosofia Bantu existe (TEMPELS, 2006, p. 11).

Para compreender da melhor forma Placide Tempels, temos que partir do debate que ele faz em torno dos conceitos de vida e morte que permitem uma maior e melhor compreensão, interpretação e percepção do $\mathrm{Muntu}^{3}$. No entanto, Tempels refere que o comportamento humano se ergue a partir de conceitos e princípios. Dai que os bantus possuem um sistema ontológico e é necessário que se encontre uma via adequada e apropriada para melhor descobri-lo.

Para Tempels, considera que em qualquer estudo "é necessário o uso de um método, pelo qual irá determinar a melhor via ou forma de definir uma exposição sistemática da filosofia Bantu justificando deste modo a sua objectividade. É preciso, mostrar a coesão das nossas propostas teóricas, e, ao mesmo tempo provando que elas são sólidas, e que elas se aplicam às realidades da vida Bantu" (TEMPELS, 2006, p. 11).

Portanto, Tempels, na sua obra, apresenta como métodos o conhecimento da língua nativa"primitiva, um estudo filosófico e jurídico da etnologia ou a maiêutica catequética podem revelar o tal sistema. Nesse contexto, essa ontologia existe: Ela penetra toda a mentalidade dos primitivos, ela domina e orienta todo o seu comportamento" (TEMPELS, 2006, p. 13).

O europeu deve usar o conhecimento que tem, sobretudo os métodos de análise e de síntese, para prestar serviço aos primitivos de modo a que possa classificar e sistematizar os elementos de seu sistema ontológico. A concepção da vida nos Bantu é centrada na Força Vital. A força vital, a vida, a força, viver forte são valores supremos do Bantu. A força vital reforça a vida ou assegura a perenidade da descendência. Ela também ajuda para afastá-lo (o Bantu) do mal ou da diminuição da vida e do ser e protege de influências aniquiladoras.

A força, a vida forte, a energia vital são objectos de orações e de invocações à Deus, aos espíritos e aos defuntos de tudo aquilo que chamaríamos de magia, adivinhos e remédios mágicos ou forças da natureza. Eles mesmo (os Bantu) dirão que eles se dirigem ao divino para aprender as palavras da vida, que ele (o divino) ensina a maneira de reforçar a vida". É neste contexto que "O bwanga - remédio mágico não deve necessariamente, segundo eles ser aplicado na ferida ou no ombro doente. Ele não tem em primeiro lugar um efeito terapêutico local, mas ele reforça, aumenta directamente a força vital ou o ser mesmo" (TEMPELS, 2006, p. 20).

A filosofia de Tempels, resume-se na ideia da força vital. Para ele, os colonizadores não compreenderam efectivamente o negro pelo facto de não terem descoberto esta dimensão tão

\footnotetext{
3 Muntu - a palavra Muntu significa pessoa na língua bantu.
} 
profunda do negro. A maior preocupação da existência do negro é aumentar a sua força vital. As suas invocações, os seus rituais são para fortalecer e aumentar a sua força vital. Nas mentes dos Bantus, todos os seres do universo possuem força vital própria; humana, animal, vegetal ou inanimado. De acordo com Tempels, a suprema felicidade, o único tipo de bênção, é, para o Bantu, a força vital: a pior desgraça e, em verdade, o único infortúnio, é que ele pensa, a diminuição desse poder.

O Bantu alude a esta força vital em suas saudações um para com o outro, o uso de tais formas de tratamento como: "Você é forte", ou "você tem a vida em você", "você tem a vida fortemente em você"; e que eles expressam simpatia em frases como "a tua força vital é reduzida", "a sua energia vital foi solapada". Uma ideia similar é encontrada na forma de simpatia.

Na visão de Tempels, a objeção, portanto, era sim uma questão de princípio do que de prática, o medo de ser fundamentado nas verdades da ontologia Bantu. Esses vários aspectos do comportamento Bantu permitem ver que a chave para o pensamento Bantu, é a ideia da força vital, da qual a fonte é Deus. Para melhor compreendermos a teoria ontológica proposta por Tempels sobre a força vital, como uma realidade, embora invisível e suprema no homem, é necessário conhecer as principais formas por ele propostas que passamos a anunciar: primeiro, a noção geral de ser, segundo, toda a força pode ser fortalecida ou enfraquecida, terceiro, a interacção de forças: um ser que influencia o outro, quarto, a hierarquia de forças e, finalmente, a quinta, o Criado Universo está centrada no homem. Estas formas serão apresentadas de forma detalhada para melhor decifrá-las, a seguir:

Primeiro, a noção geral de ser - a alma Bantu anseia vida e vigor. A noção fundamental segundo o qual o ser é concebido dentro da categoria de forças. Aqui, o africano nunca fala de força vital. Mas, entre eles, os factos são de tal forma que todo mundo conhece e ninguém precisa falar sobre elas. A força é ainda mais do que um atributo necessário dos seres; é a natureza do ser, a força é ser, ser é força. Quando pensamos em termos do conceito de Ser, eles usam o conceito de força. Onde vemos seres concretos, eles vêm forças concretas (TEMPELS, 2006, p. 23).

Segundo, toda a força pode ser fortalecida ou enfraquecida - todos os seres podem tornar-se mais fortes ou mais fracos. Dizemos a um homem que ele cresce, se desenvolve, adquire conhecimento, exerce a sua inteligência e a sua vontade; e que ao fazê-lo, ele aumenta. Assim, o desenvolvimento opera em qualidades de um homem ou em suas faculdades. A ontologia do Bantu, é radicalmente contra tal concepção. Quando um Bantu diz: "Eu estou me tornando mais forte", ele está pensando em algo bem diferente do que queremos dizer quando dizemos que os nossos poderes estão aumentando (TEMPELS, 2006, p. 27). Este é o sentido mais apropriado em que devemos compreender as expressões que foram citadas para mostrar que o comportamento do Bantu, está centrado na ideia de energia vital: "ser forte", "para reforçar a sua vida", "vocês são poderosos", "ser forte"; ou ainda, "a sua força vital está em declínio, tem sido afetada".

Terceiro, a interacção de forças: um ser que influencia o outro - é uma causalidade metafísica que se liga a criatura ao criador. A relação da criatura com o criador é uma constante. Quer dizer que a criatura é, por sua natureza permanentemente dependente de seu criador para a existência e os meios de sobrevivência. Nós não concebemos qualquer relação equivalente entre as criaturas. Os seres criados são indicados na filosofia escolar como substâncias, isto é, os seres que existem, se não por si mesmos, de qualquer forma, em si mesmos. A criança é, desde o nascimento, um novo ser, um ser humano completo. A natureza humana de uma criança não permanece na relação causal permanente com a dos seus pais.

Para o Bantu só existe interacção do Ser com o Ser, ou seja, de força com força. Transcendendo a interações psicológicas mecânica, química e, eles vêm uma relação de forças que nós devemos chamar ontológico. Essa força irá reforçar ou enfraquecer a outra. Esta causa- 
lidade não é de forma sobrenatural, no sentido de ir além dos atributos próprios da natureza criada (TEMPELS, 2006, p. 29).

Quarto, a hierarquia de forças - tal como acontece com as castas indianas e como os israelitas que distinguem o puro do impuro, os seres são diferenciados, na ontologia Bantu, em espécies de acordo com o seu poder vital ou sua posição vital inerente. Acima de tudo, a força é Deus, o Espírito criador. É ele que tem força, poder em si mesmo. Ele dá existência, o poder de sobrevivência e de crescimento, para outras forças. Em relação a outras forças, ele é aquele que aumenta a força e depois dele vêm os primeiros pais dos homens, fundadores dos diferentes clãs.

A vida pertence a uma hierarquia, e não segue simplesmente o status legal, mas como ordenado pelo seu próprio Ser, de acordo com a primogenitura e sua posição vital; isto é, de acordo com o seu poder vital. Mas o homem não está suspenso no ar. Ele vive em sua terra, onde encontra-se a ser a força vital soberana, governando a terra e tudo o que vive nele: homem, animal ou vegetal. O verdadeiro chefe, então, seguindo a concepção original e configuração política dos povos de clã, é o pai, o mestre, o rei; ele é a fonte de toda a vida, ele é como o próprio Deus. Depois da categoria de forças humanas vêm as outras forças, animal, vegetal e mineral. Mas, dentro de cada uma dessas categorias é encontrada uma hierarquia baseada no poder vital. Essa seria uma analogia fundada na primogenitura ou mediante uma ordem pré-determinada de subordinação. Um grupo humano e uma espécie animal pode ocupar em suas respetivas classes uma classificação relativamente iguais ou relativamente diferentes (TEMPELS, 2006, p.30).

Quinto, o criado universo está centrado no homem - a geração actual humana que vive na terra é o centro de toda a humanidade, incluindo o mundo dos mortos. Na mente do Bantu, os mortos também vivem, mas a sua vivência é diminuída, com redução de energia vital. Esta parece ser a concepção do Bantu quando falam dos mortos em geral, superficialmente e em relação às coisas externas da vida. Quando eles consideram a realidade interna do ser, eles admitem que seus antepassados falecidos não perderam o seu reforço influência superior; e que os mortos, em geral, adquiriram um maior conhecimento da vida e da força vital ou natural (Ibidem, p. 31). Assim, a força vital do homem branco é tal que contra ela a "manga", ou a aplicação de forças naturais activas à disposição dos africanos, foi sem efeito.

E, finalmente, as leis gerais de Vital Causalidade - o universo de forças é organicamente construído no que podemos chamar de uma hierarquia ontológica. A interacção de forças é um exercício de influências vitais que ocorre, de facto, de acordo com leis determinadas. $O$ universo Bantu não é um emaranhado caótico de forças desordenadas cegamente lutando uns com os outros. Também não devemos acreditar que essa teoria de forças é o produto de uma imaginação incoerente selvagem, ou que a acção da mesma força pode ser agora propícia e agora perniciosa, sem um poder determinante para justificar o facto (TEMPELS, 2006, p. 33).

Sumarizando, Mudimbe fez uma sistematização da teoria da Bantu Philosophy de Tempels, e descreveu-a da seguinte maneira: em primeiro lugar, os Bantus enquanto seres humanos, possuem sistemas organizados de princípios (crenças) e referências (costumes), que constituem a sua filosofia na forma implícita; em seguida, a filosofia Bantu é uma ontologia, e à medida que dedica especial atenção a noção transcendental de ser, sua vitalidade e sua relação com a sua força (força enquanto atributo e elemento necessário e inseparável do ser) permite uma compreensão e interpretação dinâmica da vida e realidade do africano; terceiro, já na ontologia Bantu, o Ser é igual à Força vital. A força vital possibilita a hierarquização dos seres existentes no universo, isto é, na ordenação das identidades, diferenças, relações e influências entre os eles (mineral, vegetal, animal, humano, ancestral e divino); quarto, a Força Vital é atribuída 
por Deus e ela pode ser fortalecida (aumentada) ou debilitada (diminuída); quinto, somente na estrutura conceptual e sistemática da filosofia ocidental podemos compreender, interpretar e tornar explícita a ontologia Bantu; e, finalmente, a ontologia Bantu é a chave para a compreensão das ontologias de todos os povos africanas (MUDIMBE, 2013, p. 176).

\section{A sabedoria e concepção do Bantu Philosophy em Placide Tempels}

De acordo com Tempels, toda a filosofia Bantu é baseada na evidência interna e externa. Se o Bantu aceita, geralmente, suas actuais crenças livre de dúvida, é porque sua sabedoria é engendrada em si, ao mesmo tempo que a sua força de vida de seus pais e antepassados, que continuam a instruí-los por meio de adivinhas. Por isso, músicas, fábulas, tradições mitológicas e cerimônias de iniciação, asseguram a instrução no pensamento Bantu.

O verdadeiro conhecimento, a sabedoria humana, é igualmente metafísica: esta será uma inteligência de forças, de sua hierarquia, sua coesão e sua interacção. Na verdade, assim como a força humana vital (seu ser) não existe por si só, mas é e permanece essencialmente dependente de seus anciãos, de modo que o poder de saber é, como o próprio ser, essencialmente dependente da sabedoria dos mais velhos. Ontologicamente e juridicamente os anciãos é que detêm a supremacia de conhecer plenamente, em última instância. Sua sabedoria excede o de outros homens (TEMPELS, 2006, p. 35).

Entretanto, pode-se afirmar que a filosofia Bantu é Metafísica ou Filosofia da Força, isto é, está dentro da capacidade de cada Bantu. A filosofia de forças é uma teoria da vida, uma Weltanschaung. É possível que ele possa ter sido inventado para justificar um determinado comportamento, ou que uma determinada adaptação da natureza, pode ter condicionado esse comportamento, mas sempre a filosofia de forças governa estritamente na verdade toda a vida Bantu. Ele explica as motivações humanas de todos os costumes Bantu. Ele decreta as normas segundo as quais, a personalidade no indivíduo deve ser mantida inalterado ou autorizado a desenvolver.

De acordo com Tempels, dentro da filosofia Bantu, existem alguns critérios que determinam todo o conhecimento do indivíduo, que se resumem em três a saber: o primeiro critério refere-se ao nome. Para ele, o nome exprime a natureza individual do Ser, ou por outra, o nome é a realidade do indivíduo. "O Muntu pode ter muitos nomes". O primeiro nome, sempre representa a individualidade ontológica do Ser. Para os Bantu o homem não é nunca um indivíduo isolado é um ser em conjunto.

O segundo critério é aquele que considera o indivíduo clánico. Este indivíduo é visto numa relação de dependência jurídica, de parentesco e sobretudo, entendido no sentido real de interdependência ontológica. Por fim, o terceiro e último critério, é o da aparência externa do homem. Para os bantus, o homem, se distingue como sendo, corpo, seu sopro e sombra. Além disso, a sua força vital pode exprimir-se de uma forma específica em certos aspectos ou modalidades de aparências externas do homem que poderíamos chamar de momentos ou de fundamentos de alta tensão vital. (TEMPELS, 2006, p. 67).

Portanto, em toda a filosofia de Tempels reside conceitos da força vital e ontológica. Por isso, ele defende um pensamento metafísico entre os Bantus e procura mostrar claramente a racionalidade do povo Bantu; pois, precisa de ser ajudado a descobrir a razão e a coerência do seu pensamento. Na verdade, Tempels tinha como objectivo principal sentir o Bantu pelo menos uma vez na vida, ou por outra, queria pensar, sentir, viver como eles, porque possuem uma alma Bantu. 
De acordo com Elungo (2012), a ideia da filosofia Bantu de Tempels trata-se efectivamente de imagem forjada. Essa imagem encontra-se claramente delineada em sua obra, a qual essa obra surgiu em resposta às objecções contra o próprio conceito de filosofia, conceito esse aplicado por ele sem fornecer uma explicação exaustiva prévia.

\section{A crítica unanimista de Hountondji à Bantu Philosophy de Tempels}

Paulin Hountondji inicia seu debate por definir a etnofilosofia proposta por Tempels como sendo um pensamento, modelo exemplar, mas uma tentação permanente do discurso africanista. Assim, a filosofia africana nasceu como sendo um aviso, um convite ou mesmo se quisermos, uma chamada de atenção para exteriorizar os demónios que muitas das vezes eram ignorados ou escondidos (HOUNTONDJl, 1996, p. 22).

Na visão de Hountondji, o objectivo principal da sua crítica unanimista visava estabelecer uma nova concepção etnológica da filosofia, a partir da proposta feita por Tempels em sua obra Bantu Philosophy. Esta crítica varia na simples equação: "Filosofia africana é igual à literatura da filosofia africana. Isto é, todos os textos que se pretendem filosóficos devem ser produzidos por africanos". O autor refere que a obra de Tempels não se equipara a uma obra filosófica do ponto de vista científico, mas sim como uma etnofilosofia, como generalização abstracta de uma interpretação metafísica da etnologia.

A possibilidade de uma literatura filosófica oral não estava excluída. Por isso, foi por esta razão que convocou o diálogo com velho Ogotemmeli, que em poucas páginas, contribuiu grandemente em relação à Filosofia Bantu de Placide Tempels. Desta forma, para que se reconheça a liberdade do pensamento africano, temos que nos libertar de todos tipos de doutrinas essencialistas e particularistas, surgidas a 100 anos no africanismo. Esta necessidade pressupõe, lidar com a complexidade da nossa história, trazer de volta o cenário dessa história, à sua simplicidade original, com vista a lidar com a riqueza das tradições africanas, de forma a enfraquecer o conceito de África, libertar este conceito de todas as conotações étnicas, religiosas, filosóficas, políticas, etc.; incutidas por tradições antropológicas longas, estabelecidas previamente (HOUNTONDJI, 2002, p. 47).

Na perspectiva de Hountondji, a filosofia africana é um "conjunto de textos, textos que são especialmente escritos por africanos e descritos como sendo filosóficos pelos próprios autores" (HOUNTONDJI, 1996, p. 9). Pode-se perceber no pensamento de Hountondji três (3) aspectos levantados contra aquilo que vários leitores consideram e definem como filosofia africana, a saber: por um lado, que a nacionalidade e a localização geográfica do autor não são condições suficientes para a africanidade, mas sim, sugere que algo a mais se deve incluir ligado à causa africana; por outro lado, as intenções pessoais do autor e a sua auto-crítica não devem constituir razão suficiente para designar um trabalho qualquer de filosófico; por fim, a objeção mais contundente, faz menção à quantidade de textos escritos, a restringir, o que de certa forma é arbitrário e ambíguo. Outrossim, são as formas de termos filosóficos e a falta de atenção que se dão às expressões da literatura oral que são extraordinariamente ricas.

Portanto, a filosofia africana como qualquer outra filosofia, "não pode ser uma visão colectiva do mundo", mas sim, como uma filosofia que consiste na confrontação de pensamentos individuais, duma discussão e debate.

Por seu turno, ao falar de filosofia africana, Hountondji refere-se à literatura e tenta compreender, porque, até então, tem feito um esforço extremo para se esconder por de trás de algo; tudo o que mais obscuro por ser imaginário, de uma filosofia implícita concebida como um 
sistema impensado, espontâneo, colectivo do pensamento, comum a todos os africanos; ou pelo menos, a todos os momentos, passado, presente e futuro, de um grupo étnico africano.

Neste contexto, Hountondji, procurou entender o porquê da forma como os autores africanos, quando tentam se engajar na filosofia, pensavam ser necessário projectar a realidade incompreendida do seu próprio discurso sobre tal ficção palpável. E o que está em jogo na visão do autor, é a ideia de filosofia ou melhor, de filosofia africana. Concretamente, "o problema é se a palavra filosofia, quando qualificada pela palavra africana, pode manter o seu significado habitual, ou se a simples adição de um adjectivo, necessariamente, muda o significado do substantivo. Portanto, o que está em questão é a universalidade da palavra filosofia através das suas possíveis aplicações geográficas" (HOUNTONDJ, 1996, p. 56).

Numa outra abordagem, Ngoenha considera que a crítica à teoria de Tempels é considerada como um sistema se articula em volta do conceito da força vital que, por sua vez, coincide analogicamente com o conceito do Ser. Enquanto a metafísica ocidental tem um carácter estático, a metafísica Bantu tem um carácter dinâmico. $O$ importa referir é que a filosofia das forças vitais deve ser compreendida como uma filosofia da vida, noção que invade e condiciona a vida dos Bantus. Por isso a ontologia Bantu constitui a vida comum de todos os povos primitivos, clássicos.

Todavia, o trabalho de Tempels, segundo Hountondji, é tido como referência para recordar as suas ideias sobre a filosofia, o significado da palavra filosofia na sua tese "Bantu Philosophy". Mais do que uma vez, Tempels enfatizou que a filosofia é resultado de um conhecimento adquirido na prática, mas não pelo pensamento, e que, os seus praticantes são e devem, na melhor das hipóteses, serem conscientes disso. Como defende Hountondji,

nós não reivindicamos que bantus sejam capazes de nos apresentar com um tratado filosófico completo, com um adequado vocabulário, mas sim, é a nossa própria formação intelectual que permite com que seus efeitos sistemáticos para o desenvolvimento, cabe a nós proporcionar um relato preciso da sua concepção de identidade de tal forma que possam ser reconhecidos nas nossas palavras e concordar nelas. Por sua vez, "vocês nos entenderam, vocês nos conhecem completamente, vocês sabem da mesma forma como nós sabemos (HOUNTONDJI, 1996, p. 57).

De facto, o significado da palavra Filosofia foi equivalente ao salto de uma exposição da natureza profundamente conservadora do próprio projecto etnofilosófico. Ela segue não só o percurso da filosofia Bantu, mas, também, toda a literatura etnofilosófica deve ser submetida a uma versão profunda da política do criticismo de Césaire. Para que o seu resultado fosse positivo, deveria ser chamado de trabalho etnológico (um tipo de equivalência científica de luta, batalha militar para o $3^{\circ}$ mundo pelas grandes potências).

Assim sendo, Tempels pode ser considerado um grande especialista na área Bantu pelo facto da sua reconstrução filosófica africana ser a mais sensacional por causa do seu contraste para com a pseudofilosofia imaginária europeia, e que semelhantes tentativas foram feitas por outros autores europeus para outras regiões de África. Todavia, isto significa que os autores são obrigados a conceber a filosofia do modelo da religião, como permanente sistema estável de crenças, não afetado pela evolução impermeável ao tempo e a história é até mesmo idêntica a si mesma. Estes autores não estavam tão motivados como os etnográficos da igreja, não obstante, estavam com a intenção de localizar, sob as diversas manifestações da civilização africana, sobre o dilúvio da história que percorreu esta civilização bem como o mal, que pode fornecer uma base de certezas: em outras palavras, um sistema de crenças.

Voltando ao mito da unanimidade, Hountondji considera que à primeira vista este consenso técnico postulado por etnofilósofos, entre todos os membros de cada sociedade 
ou comunidade primitiva devem produzir um consenso paralelo, a nível dos resultados, senão de métodos, entre todos os etnofilósofos estudando a mesma comunidade. Porém, ao invés de um consenso ideal, uma nítida unanimidade cuja transparência teria revelado a unanimidade espontânea de todos os filósofos primitivos, literatura etnofilosófica que nos oferece não só uma rica coletânea de trabalhos diversos, mas também, por vezes francamente contraditórios.

Para Appiah (1997, p. 146), a etnofilosofia teve um começo útil, apresenta um ponto de partida para a negociação da vida conceitual, o que, em certo sentido, equivale a dizer a vida tout court dos africanos contemporâneos. Por isso, a etnofilosofia é meramente um passatempo. Contudo, o conceito de filosofia africana, é co extensivo ao conceito cultural. É obtido por oposição ao comportamento animal. Assim, diferencia-se de tal comportamento, mas continua indiscernível de qualquer forma cultural: mito, religião, poesia, arte, ciência etc. Wiredu e Hountondji partilham dessa crença, para eles, ao explorarmos as actuais opções filosóficas de África, estaremos a voltar a eles.

Ainda na perspectiva de Appiah, considera que a importância de ele ser africano, tanto é mais global, em certo sentido, quanto mais local, em outro; mais local porque, como implica, ele fala em ganês em nome de uma cultura africana, mais global por ele indagar o que, afinal, a particularidade de sua experiência ganesa pode oferecer à comunidade filosófica fora da África (APPIAH, 1997, p.150).

De acordo com Sousa et Meneses (2009, p. 124), uma das implicações imediatas disto foi a seguinte: "o novo conceito de filosofia africana permitiu estabelecer uma distinção entre africanistas e africanos no campo filosófico". Visto que muitos dos pensadores ocidentais que escreviam sobre os sistemas de pensamento africanos deixaram de poder ser vistos como pertencentes à filosofia africana entendida neste novo sentido; uma outra implicação é que, a filosofia africana também inclui escritos que criticam ou põem em causa a etnofilosofia. Isto é um indício de claro de que não existe qualquer unanimidade em África sobre esta questão concreta.

Em suma, a única coisa que esta objeção negligencia é a pequena diferença citada entre a ciência e a etnofilosofia, que não exige qualquer resultado comparável com a suposta unanimidade da comunidade humana, que nestas ciências, além disso, a contradição nunca está estagnada, mas sempre progressiva, nunca definitiva ou absoluta, mas um indicativo de um erro, da falsificação de uma hipótese ou tese, que é obrigada a emergir através duma pesquisa racional do próprio objecto, enquanto circular, uma vez que nunca podem ser resolvidos por meio da experiência de qualquer outro instrumento ou método de verificação. Uma das fortes objeções de Hountondji aos etnofilósofos decorre de uma visão essencialmente althusseriana do lugar da filosofia; e o seu recurso a Althusser contrasta duma forma marcante aos apelos de Wiredu a Dewey, e reflecte claramente a distinção entre as tradições francófonas e anglófonas.

\begin{abstract}
Para o Bantu, identidade ou Ser é poder e Kagamé discordou com esta tese, considerando que não existem meios de resolver esta disputa. Portando, está mais que claro que a filosofia bantu de um não é a filosofia do bantu, mas sim do Tempels, que o bantu Ruandês do outro não é do Ruandês, mas de Kagamé. Na perspectiva de Hountondji, ambos simplesmente fazem o uso das tradições africanas e da literatura oral, e projetam sobre eles as suas próprias crenças filosóficas, na esperança de melhorar a sua credibilidade (HOUNTONDJ, 1996, p. 62).
\end{abstract}

Sumarizando, é desta forma que funciona a tese dos trabalhos de uma filosofia colectiva africana, em que, é tida como uma cortina de fumaça, a forma pela qual, cada autor é capaz de 
manipular os seus pontos de vista filosóficos. Não tem nada para além desta função ideológica, é apenas um discurso indeterminado sem nenhum objecto.

\section{Novo paradigma conceitual de Filosofia Africana Contemporânea}

Actualmente, o debate contemporâneo sofreu uma acentuada transformação, tanto em relação ao tipo de questões, como à forma como estas são articuladas. O desafio colocado ao filósofo africano contemporâneo é o de, na filosofia africana, apartar o mito da realidade, isto é, separar as cascas das sementes, a pseudofilosofia africana da autêntica filosofia africana. "A filosofia africana contemporânea está enraizada por todo o continente, e estende os seus ramos a outros continentes onde haja africanos, pessoas de origem africana ou autores não africanos que abordem temas africanos, empenhados na formulação do pensamento actual da filosofia africana, particularmente na Europa e na América" (cf. LOPES, 2018, p. 16).

A preocupação dominante na reflexão de significativa parcela de filósofos africanos a partir dos anos 50, em especial nos anos 60 e 70, foi elaborar uma filosofia própria, africana, enraizada em seu contexto histórico e social que sofria transformações profundas com o processo de descolonização pelo qual passavam vários povos africanos. Marcada pelas condições contextuais do próprio exercício do filosofar, tal elaboração girava - segundo alguns comentadores - em torno de dois aspectos: "a) O exame das condições necessárias para a emergência de uma verdadeira filosofia africana. b) A insistência sobre o problema das transformações culturais e, no sentido mais amplo, sobre a questão política" (MANCE, 1995, p. 20).

Existem diversos factores que motivaram, para o empreendimento inicial filosófico africano. Sem serem exaustivos, estes factores ilustram claramente o ambiente geral do começo da especulação filosófica africana, no início do século XX, a saber: Em primeiro lugar, alguns pensadores manifestavam o grande desejo de demonstrar a autêntica contribuição africana para a civilização humana e, por conseguinte, pretendiam quer desvendar uma filosofia africana que precede qualquer contacto com o Ocidente; em segundo lugar, eles estavam motivados em mostrar que, contrariamente à crença da maioria dos etnógrafos e antropólogos sociais europeus, os africanos não tinham uma mentalidade pré-lógica ou não lógica, e que, por conseguinte, podiam elaborar uma filosofia propriamente dita; em terceiro lugar, outros desejavam ainda mostrar que existia uma concepção do universo singularmente africana, sobre a qual se fundava um determinado modo de existência (MAKUMBA, 2014, p. 22).

Curiosamente, muitos temas tratados por filósofos africanos deste período são semeIhantes aos tratados por filósofos latino-americanos na mesma época. Entre eles estão o carácter e a finalidade da filosofia, o mimetismo na cultura colonizada, a alienação cultural, a relação entre o Eu e o Outro fora dos parâmetros da racionalidade europeia, a distinção de uma razão branca e uma razão negra, a relação entre filosofia e revolução, a questão da consciência e libertação nacionais, a dialética da identidade, diversidade cultural e humanismo, filosofia e religião, filosofia e subdesenvolvimento, a filosofia como fator de libertação e a responsabilidade do filósofo em meio ao seu contexto histórico.

A filosofia africana encontrou finalmente uma base sólida, principalmente pela atenção dada à erudição formal, que o pensamento contemporâneo abraçou com paixão. Nkrumah, Senghor, Keita, Oruka, Olela, Wiredu, Hountondji, Bodunrin, Tempels, Césaire, Fanon, Neugebauer, Ngoenha, Castiano, etc., são hoje nomes facilmente identificáveis nos livros de filosofia, devido a sua contribuição para o desenvolvimento da filosofia africana como uma actividade científica (MAKUMBA, 2014, p. 128). 
Por isso, para falar da filosofia africana no novo sentido devemos esboçar uma linha dentro da literatura etnofilosófica em geral, entre escritos africanos e não africanos, não porque uma categoria é melhor que a outra, ou porque ambas não poderiam, em última análise, dizer a mesma coisa, mas porque na questão de ser filósofo africano não podemos excluir a variável geográfica, tomada aqui como empírica, acidental, extrínseca ao conteúdo ou significado do discurso e à margem de qualquer conexão técnica (HOUNTONDJI, 2002, p. 64).

O século XXI promete ser ainda mais fecundo, dando maior atenção ao papel da filosofia no desenvolvimento e emancipação económica do continente africano. Assim, a filosofia africana não pode, contudo, olhar simplesmente para o lado, esperando que sejam outras as ciências que conduzam o continente a este nível. O papel da filosofia, numa sociedade que se torna cada vez mais industrializada e dependente da tecnologia, nunca pode ser suficientemente sublinhado. A filosofia africana encontra-se no cerne da formação e transformação cultural, processo em que é chamada a oferecer uma orientação. Portanto, a filosofia africana deve evidenciar-se como ma autêntica consciência no contexto da exaltação do desenvolvimento, para que a sociedade possa ser defendida de posições extremas, como as do cientismo e do tradicionalismo.

Pode-se compreender que a crítica que Hountondji faz sobre o método e a motivação conduz naturalmente a suas recomendações. Sua análise inicial é que devemos pensar na filosofia africana, não por ela dizer respeito a conceitos ou problemas africanos, mas porque ela é a parte do discurso universal da filosofia que é feita por africanos. Contudo, o trabalho de Tempels, segundo Hountondji, apesar de lidar com o sujeito africano, desempenhou um papel decisivo no desenvolvimento da etnofilosofia africana pertencente a literatura científica europeia, da mesma forma como a antropologia em geral, que apesar de lidar com sociedades não ocidentais, é uma encarnação da ciência ocidental, nem mais, nem menos. Como defendem Sousa e Meneses,

Existe algo que complementa as duas tradições de discurso e difundem uma da outra. Por um lado, ao discutirem a etnofilosofia, os filósofos africanos contribuíram, por vezes de forma indireta para um debate mais alargado, apesar dos seus objectivos imediatos e a linguagem que desenvolveram serem mais política do que epistemologicamente definidos; por outro lado, os filósofos que discutem a natureza das teorias científicas emprestaram as suas vozes ao debate da etnofilosofia, também indiretamente, apesar de os seus objectivos imediatos e a linguagem dos seus escritos serem, quase sempre, apenas epistemologicamente orientados (SOUSA \& MENESES, 2009, p. 507).

Por sua vez, Appiah, critica Hountondji pelo facto de este rejeitar a possibilidade de que haja temas e conceitos especificamente africanos que mereçam um estudo filosófico; ele parece ter extraído uma conclusão por demais radical de sua crítica à etnofilosofia. Para Appiah, "se os filósofos pretendem contribuir no nível conceitual para a solução dos verdadeiros problemas da África, eles precisam sim, começar por uma compreensão profunda dos mundos conceituais tradicionais em que habita a maioria dos seus compatriotas" (APPIAH, 1997, p. 147).

Castiano (2010, p. 100), por sua vez, concorda e dá razão a Hountondji, visto que ele "queria libertar a filosofia africana das amarras da tradição oral, do tradicionalismo, isto é, do hábito de uma filosofia que, logo à sua nascença e à semelhança da tradição, só transmite consenso". Em outras palavras, a intenção de Hountondji era desmistificar o conceito de uma África homogénea no pensamento. Eolhando para o desenvolvimento da filosofia num plano mais amplo, Hountondji é aquele que, segundo Castiano, se desculpa de ter exagerado a sua definição: passamos a citar "I would probably not use the same words today (HOUNTONDJl, 2002, p. 22).

Sumarizando, Hountondji distrai a dominante concepção mitológica dos africanos e restaura a simples verdade, óbvia que a África é acima de tudo um continente e a sua concepção é 
de um conceito geográfico empírico e não uma metafísica. O propósito desta desmitologização da ideia de África e filosofia africana é, simplesmente, para libertar a nossa faculdade de teorizar e que todos os impedimentos e preconceitos que estão por detrás dos intelectuais que até então impediram o seu avanço devem sair do chão.

\section{Considerações finais}

Para descrever a crítica unanimista de Hountondji à filosofia Bantu de Tempels, pressupõe, dizer que, não existe mais dúvida sobre a inexistência de filosofia africana, embora o seu significado seja diferente. Podemos resumir o pensamento de Tempels como sendo uma metafísica que tem por detrás a ideia da força vital. A maior preocupação dele foi de ter admitido a existência duma filosofia Bantu do negro e a necessidade dele de aumentar a sua força vital. As suas invocações, os seus rituais são para fortalecer e aumentar a força vital. Nas mentes dos Bantus, todos os seres do universo possuem força vital própria: humano, animal, vegetal ou inanimado.

Conclui-se que, Tempels entende o pensamento dos Bantu como sendo lógico e ontológico simultaneamente, que significa, palavra e coisa: palavra que designa directa e inequivocamente um aspecto da realidade. Por isso, existe uma correspondência perfeita entre o conceito e o real, o sistema de conceitos e do sistema de coisas enunciadas, designadas, (nomeadas).

Em contrapartida, na teoria de Hountondji percebe-se que está patente dentro da etnofilosofia uma falha de Tempels de ter criado uma visão colectiva dos africanos e, por esta linha de pensamento, tentar revelar-se como a única forma de conhecimento possível no seio dos africanos, favorecendo deste modo o mito da unanimidade primitiva (que privilegia o consenso), anulando a individualidade e/ou a subjectividade e impossibilitando o debate e a confrontação, próprios da filosofia e responsáveis pelo dinamismo e vivacidade desta. Portanto, toda a filosofia africana que se quer autêntica e séria deve resultar de discursos sobre assuntos africanos. $\mathrm{O}$ africano não pode permanecer numa atitude de incerteza e de indecisão, no horizonte das certezas parciais proporcionadas pelo seu contacto com outras culturas mais científicas, num mundo em rápida transformação. Enfim, os povos africanos têm de aprofundar cada vez mais as suas experiências existenciais, e procurar retirar daí as verdades quanto ao seu próprio lugar no mundo.

Outro aspecto pertinente, avançado por Hountondji, é de que a universalidade se torna possível apenas quando os intervenientes são dados a liberdade de realçar a si próprios em face de outros; e a melhor forma de alcançarmos isto na África actual, é recolher as discussões internas e compartilhar com os demais cientistas do continente, destro de cada área do saber. Não podemos continuar a agir ou actuar a parte indefinidamente, chegou o momento de sermos responsáveis da nossa própria realidade ou mesmo, fautores da nossa própria história, e porquê não, da nossa própria filosofia.

Sumarizando, é possível detetarmos sinais de um novo espírito filosófico em que a libertação deste novo espírito é a pré-condição sine qua non para qualquer progresso científico e filosófico. Mas para que isso aconteça, devemos partir do início, restaurando o direito ao criticismo e à liberdade de expressão que tem sido bastante ameaçada pelos nossos regimes e ideologias complicadas. Podemos ainda, crer que a tarefa mais importante dentro da literatura filosófica africana é transformar a literatura filosófica africana de uma simples colecção de escritas direcionadas a leituras não africanas e consequentemente sustentar a particularidade da chamada visão africana do mundo que é hoje um veículo crucial de liberdade e discussões in- 
flexíveis entre os próprios filósofos africanos; somente assim que esta literatura irá adquirir valores universais e enriquecer o seu legado comum internacional do pensamento humano, através de um diálogo intercultural ou mesmo se quisermos duma intersubjectivação.

Em suma, a filosofia africana tornou-se uma característica fundamental e necessária do discurso filosófico contemporâneo e é, actualmente, um instrumento indispensável na formação da cultura humana. Ela faz parte de uma civilização, a civilização africana; mas mesmo esta civilização africana faz ainda parte do progresso para a realização do ser humano. Por isso, a necessidade de ser reconhecida a sua contribuição.

\section{Referências}

APPIAH, A. Kwame. Na Casa do meu Pai: A África na Filosofia da cultura. Rio de Janeiro: Contraponto, 1997.

BONO, L.. Muntuísmo: A ideia da "pessoa" na Filosofia Africana. 2a edição. Portugal: Paulinas Editora, 2015.

BONO, L.; CASTIANO, P.; PROCESI, L. Filosofia Africana: Da tradição à traição. Maxixe: UNISAF Editora, 2019.

CASTIANO, P. José. Referenciais da Filosofia Africana: Em busca da Intersubjectivação. Maputo: Ndjira Editora, 2010.

CHIZIANE, P. O canto dos Escravos. Maputo: Matiko e Artes Ltda., 2017.

ELUNGO, P. E. A. O despertar filosófico em África. Lisboa: Pedago Editora, 2014.

HOUTONDJI, J. African Philosophy: Myth and Reality. 2a edição, EUA: Indiana University Press, 1996.

HOUTONDJ, J. The Struggle for Meaning: Reflections on Philosophy, culture, and democracy in Africa. Ohio: Ohio University Center for International studies, 2002.

MANCE, A. As filosofias africanas e a temática de libertação. Curitiba: IFIL, 1995.

NGOENHA E.; CASTIANO, P. Pensamento Engajado: ensaios sobre Filosofia Africana, Educação e Cultura Política. Maputo: Editora Escolar, 2011.

LOPES, F. Filodramática: Os PALOP, entre a filosofia e a crise de consciência histórica. Portugal: Paulinas Editora, 2018.

MAKUMBA, M. Introdução à Filosofia Africana: Passado e Presente. Portugal: Paulinas Editora, 2014.

MUDIMBE, V. Y. A Invenção de África: Gnose, Filosofia e a ordem do Conhecimento. Portugal Edições Pedago e Mulemba, 2013.

SANTOS, B. Sousa; MENESES, M. Paula. Epistemologias do Sul. Coimbra: Almedina Editora, 2009.

TEMPELS, P. Philosophie Bantu. Paris: Présence Africaine, 2006.

TEMPELS, P. A Filosofia Bantu. Trad. P. Casimiro Facco. Portugal: Paulinas Editora, 2019. 


\section{Sobre os autores}

\section{Tiago Tendai Chingore}

Doutorado em Filosofia na Universidade Pedagógica. Fez o programa Científico Avançado de Doutorado Sandwich em Filosofia pela UFC-Brasil. Actualmente Director Adjunto para Pós-graduação na FLH, Professor de Ética Política, Filosofia de Direito, Filosofia Política, Deontologia Profissional, TCC na Faculdade de Letras e Humanidades, Departamento de Filosofia e Ciências Sociais na Universidade Licungo, Extensão da Beira. Pesquisador e Coordenador do Núcleo de pesquisa sobre Cultura e Desenvolvimento: Modernizando às Tradições do CEMEC (Centro de Estudos Moçambicanos e Etnociências). Pesquisa sobre questões da Educação, Ética, Política, Filosofia Intercultural (Saberes locais) no contexto africano e moçambicano.

\section{Elnora Gondim}

Doutorado em Filosofia pela PUCRS. Professora de Filosofia da UFPI.

Recebido em: 15/07/2020.

Aprovado em: 29/10/2020.
Received: $15 / 07 / 2020$.

Approved: 29/10/2020. 